\title{
INFLUENNCIA DA TEMPERATURA E DO TEMPO NA EXTRAÇÃO AQUOSA DE COMPOSTOS FENÓLICOS DO CUBIU (Solanum sessiliflorum Dunal)
}

\author{
G. H. ROSSATTO ${ }^{1}$, F. B. FERREIRA ${ }^{1}$, M. M. M. BINDES ${ }^{1}$, V. L. CARDOSO ${ }^{1}$ e M. H. M. \\ REIS $^{1}$ \\ ${ }^{1}$ Universidade Federal de Uberlândia, Faculdade de Engenharia Química \\ E-mail para contato: gustavorossatto@hotmail.com
}

\begin{abstract}
RESUMO - A extração aquosa de compostos fenólicos do cubiu (Solanum sessiliflorum Dunal) foi avaliada nas temperaturas de $25,60,80$ e $90^{\circ} \mathrm{C}$ ao longo de 120 min. Observou a influência direta do tempo e da temperatura na concentração final de compostos fenólicos em solução. A temperatura de extração de $80^{\circ} \mathrm{C}$ com o tempo de 70 min apresentou o maior resultado de compostos fenólicos em solução no valor de $153,65 \pm 4,11 \mathrm{mg}$ EAG/100 g de fruto. O decréscimo dos compostos fenólicos foi observado na temperatura de $90^{\circ} \mathrm{C}$ após 70 min de extração. $\mathrm{O}$ aumento da temperatura acima de $80^{\circ} \mathrm{C}$, assim como tempos de extração maiores que $70 \mathrm{~min}$, provavelmente resultou na degradação dos compostos fenólicos. As condições mais favoráveis encontradas deverão ser utilizadas em trabalhos futuros para concentração dos compostos fenólicos presentes no extrato.
\end{abstract}

\section{INTRODUÇÃO}

O cubiu (Solanum sessiliflorum Dunal) é uma solanácea arbustiva com ciclo anual, distribuída em toda a Amazônia, sendo o fruto consumido pelas populações locais. A polpa, de coloração amarelada, apresenta alto rendimento e baixo grau de doçura. O cubiu apresenta inúmeras utilizações que podem atrair a atenção para o mercado nacional e internacional devido as suas características (Fujita; 2011). Yuyama et al. (2008) observaram a ação hipoglicemiante do cubiu em seu estudo utilizando ratos. Contudo, o consumo deste fruto é restringido devido à pericidade do fruto e questões culturais. A possibilidade de processamento deste fruto para uso das indústrias de alimentos e farmacêutica deverá impulsionar a comercialização desta fruta, que apresenta elevado potencial em termos de compostos bioativos.

Não há um método satisfatório para a extração de todos ou de uma classe específica de fenólicos presentes nos alimentos. Muitas técnicas têm sido exploradas para a extração de polifenóis possuindo vantagens e desvantagens, sendo que a extração exclusivamente aquosa possui a vantagem de não requerer a etapa de retirada posterior do solvente orgânico. $\mathrm{O}$ branqueamento pode ser utilizado como uma forma de inativação enzimática. Miranda et al (2010) observaram que esta técnica trouxe resultados positivos devido a manutenção dos compostos fenólicos do suco de maça.

Dessa forma, o presente trabalho tem como objetivo avaliar a extração aquosa de compostos fenólicos do cubiu submetidos ao processo de branqueamento. Avaliou-se o efeito 
das variáveis operacionais: tempo e temperatura, visando maximizar a extração dos compostos de interesse.

\section{MATERIAIS E MÉTODOS}

\subsection{Materiais}

O Cubiu foi adquirido no mercado local de Manaus - AM. Água destilada foi utilizada como solvente e para determinação de compostos fenólicos utilizou-se Folin- Ciocalteau (Dinâmica), carbonato de sódio anidro (Vetec) e ácido gálico (Vetec).

\subsection{Preparação do extrato bruto e inativação enzimática}

Os frutos foram lavados e selecionados e em seguida, com o auxílio de facas, fatiados em cubos com aproximadamente $1 \mathrm{~cm}^{3}$. A amostra global foi homogeneizada e fracionada em embalagens plásticas de $50 \mathrm{~g}$ e então estocada em freezer a $-25^{\circ} \mathrm{C}$ até o momento de utilização. Aos frutos fatiados e congelados foi adicionada água destilada obtendo uma solução heterogênea com uma relação mensurável de fruta em água (massa do fruto/massa total) na proporção de $10 \%$. A mistura foi triturada com o auxílio de um mixer doméstico (Mixer Cadence Fast Blend) por 3 min obtendo uma polpa uniforme. A polpa aquosa homogeneizada foi submetida ao processo de inativação enzimática onde se seguiu-se a metodologia descrita por Yuyama et al. (2006) com modificações. A inativação enzimática seguiu as seguintes etapas: a polpa triturada foi acondicionada em um saco plástico e então foi imersa em um banho de água à temperatura de $90^{\circ} \mathrm{C}$ por um período de 5 minutos em seguida a polpa foi submetida a um choque térmico em banho de gelo.

\subsection{Influência do Tempo e Temperatura}

Para a avaliação da influência da temperatura e do tempo na extração dos compostos fenólicos foram utilizadas as temperaturas de $25,60,80$ e $90^{\circ} \mathrm{C}$. A solução foi mantida sobre uma chapa de aquecimento direto com controle de temperatura e agitação envolta com papel alumínio para minimizar a influência da luz. Amostras foram colhidas ao longo do tempo para análise do teor de compostos fenólicos totais.

\subsection{Determinação dos Compostos Fenólicos Totais}

O teor de compostos fenólicos totais (TCF) foi determinado de acordo com Singleton et al. (1999) pelo método Folin-Ciocalteau com adaptações. Uma alíquota de 0,125 mL do polpa foi colhida no tempo e temperatura especificada, a amostra coletada foi transferida para um tubo de ensaio e na sequência adicionado $0,125 \mathrm{~mL}$ de Folin-Ciocalteau diluído em água (1:2 em volume). Após $5 \mathrm{~min}$ em repouso foram adicionados $2,25 \mathrm{~mL}$ de solução aquosa de carbonato de sódio anidro $(28 \mathrm{~g} / \mathrm{L})$. A solução foi homogeneizada e mantida em repouso, na ausência de luz, por $1 \mathrm{~h}$. Em seguida, foi realizada a leitura da absorbância em espectrofotômetro a $725 \mathrm{~nm}$ (UV - 1240 Shimadzu). Os resultados foram expressos em mg de equivalente de ácido gálico (EAG) em $100 \mathrm{~g}$ de fruto. 


\section{RESULTADOS E DISCUSSÃO}

Tabaraki et al. (2012) relataram que o aquecimento de extratos vegetais na faixa de temperatura entre $52^{\circ} \mathrm{C}$ e $67^{\circ} \mathrm{C}$ pode amolecer o tecido da parede celular e hidrolisar os compostos fenólicos ligados, consequentemente aumentando sua solubilidade. $\mathrm{O}$ aumento da temperatura auxilia de forma positiva a extração de compostos fenólicos, no entanto algumas classes são termossensíveis, sendo necessário manter a temperatura de extração abaixo de $65,2^{\circ} \mathrm{C}$ (Silva et al., 2007). Na extração do cubiu observou-se que somente na temperatura de $90^{\circ} \mathrm{C}$ e após 70 min de extração ocorre o decaimento da concentração dos compostos fenólicos indicando que estes possuem uma maior resistência a temperatura.

De acordo com a Figura 1, observa-se que o tempo e a temperatura influenciam diretamente na extração de compostos fenólicos do cubiu. A análise dos resultados experimentais comprova que o aumento da temperatura favorece a solubilidade dos compostos fenólicos até a temperatura de $80^{\circ} \mathrm{C}$ e após $70 \mathrm{~min}$ de extração não houve incremento significativo na concentração de compostos fenólicos em solução.

Figura 1. Cinética de extração de compostos fenólicos em função da temperatura

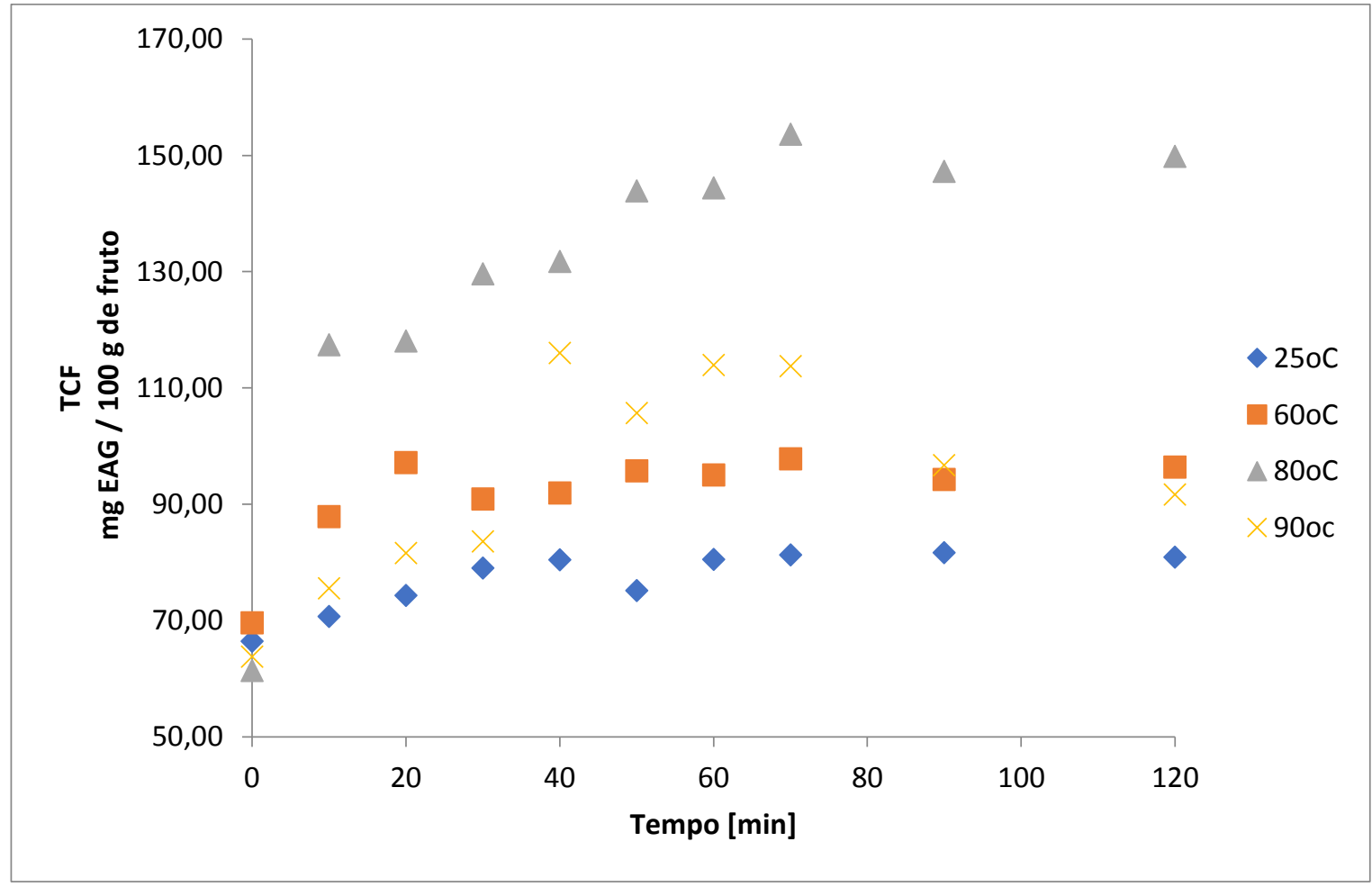

Tradicionalmente a extração de compostos fenólicos do cubiu é realizada com o auxílio de compostos orgânicos, geralmente acetona e/ou metanol. Durante a extração não há verificação de influência da temperatura e do tempo na concentração dos compostos fenólicos ao longo da extração. Na Tabela 1 estão apresentados alguns valores disponibilizados na literatura. 


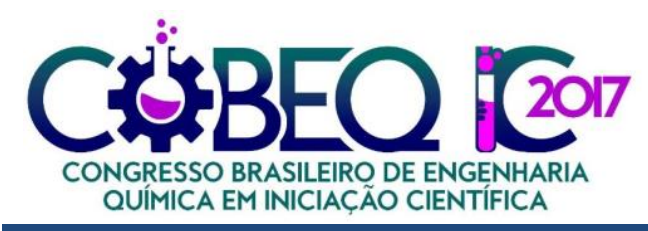

XII Congresso Brasileiro de Engenharia Química
em Iniciação Científica
UFSCar - São Carlos - SP
16 a 19 de Julho de 2017

Tabela 1 - Comparativo dos valores de compostos fenólicos em extratos de cubiu.

\begin{tabular}{|c|c|c|c|}
\hline Referência & Solvente & Diluição da polpa & TCF $\left(\mathrm{mgEAG} 100 \mathrm{~g}^{-1}\right)$ \\
\hline $\begin{array}{c}\text { SILVA FILHO; } \\
1999\end{array}$ & $\begin{array}{c}\text { Metanol-água } \\
(50: 50 \mathrm{v} / \mathrm{v})\end{array}$ & $\mathrm{NE}$ & $12,24 \pm 2,59$ \\
\hline $\begin{array}{c}\text { FURLANETO; } \\
2015\end{array}$ & $\begin{array}{c}\text { Acetona-água } \\
(80: 20 \mathrm{v} / \mathrm{v}) .\end{array}$ & $\begin{array}{c}(1: 10) \\
(\mathrm{g} \text { fruto/ml solvente) }\end{array}$ & $53,50 \pm 8,51$ \\
\hline Este trabalho & Água & $\begin{array}{c}(1: 9) \\
\text { (g fruto/g solvente) }\end{array}$ & $153,65 \pm 4,11$ \\
\hline
\end{tabular}

NE: não especificado

A comparação entre os valores encontrados nos diferentes trabalhos é inadequada uma vez que envolvem diferentes formas de extração, entretanto observa-se uma coerência na ordem de grandeza dos valores reportados com os obtidos nesse trabalho. Ainda, as melhores condições de extração em termos de temperatura e tempo devem ter favorecido o ligeiro aumento no teor de compostos fenólicos deste trabalho.

O extrato de cubiu apresentou teor de compostos fenólicos semelhantes a outras frutas exóticas, tais como Platonia insignis (bacuri) $\left(23,8 \mathrm{mg}^{\mathrm{EAG}} 100 \mathrm{~g}^{-1}\right)$, Spondias mombin (cajá) (72,0 mg EAG $100 \mathrm{~g} \mathrm{~g}^{-1}$ ), Spondias tuberosa (umbu) (90,4 mg EAG 100 g $\left.{ }^{-1}\right)$, Hancornia speciosa (mangaba) (169,0 EAG 100g-1) and Eugenia pyriformis (uvaia) (127,0 mg EAG 100g ${ }^{-1}$ ) (Rufino et al., 2010), ou mesmo quando comparado com outras frutas tradicionais como abacate (106 mg EAG $100 \mathrm{~g}^{-1}$ ) e manga (121 mg EAG $100 \mathrm{~g}^{-1}$ ) (Gregoris et al., 2013).

\section{CONCLUSÃO}

A temperatura e o tempo influenciaram diretamente na extração de compostos fenólicos do cubiu (Solanum sessiliflorum). Após 70 min de extração obteve-se a máxima concentração de compostos fenólicos em todas as temperaturas de extração e após este período observou-se o decaimento destes somente na temperatura de $90^{\circ} \mathrm{C}$ o que indica uma possível degradação destes bioativos. A maior concentração de compostos fenólicos em solução foi obtida na temperatura de $80^{\circ} \mathrm{C}$ após 70 min de extração com o valor de 153,65 $44,11 \mathrm{mg}$ EAG/100 g de fruto.

\section{AGRADECIMENTOS}

Os autores agradecem à UFU (Universidade Federal de Uberlândia), a CAPES (Coordenação de Aperfeiçoamento de Pessoal de Nível Superior), à FAPEMIG (Fundação de Assistência à Pesquisa de Minas Gerais) e ao CNPq (Conselho Nacional de Desenvolvimento Cientifico e Tecnológico) pelo aporte financeiro.

\section{REFERÊNCIAS}

FUJITA, E. Temperatura, Embalagem e Radiação Gama na Conservação Póscolheita De Maná Cubiu. Tese de doutorado 2011 
FURLANETO, K. A. Qualidade Nutricional e Aceitabilidade da Geleia Convencional e Light de Maná Cubiu Dissertação de Mestrado. Faculdade de Ciências Agronômicas da Unesp - Campus de Botucatu.

GREGORIS, E., LIMA, G.P.P., FABRIS, S., BERTELLE, M., SICARI, M., STEVANATO, R. Antioxidant Properties of Brazilian Tropical Fruits by Correlation between Different Assays. Biomed Res Int. Artn 132759, 2013.

MIRANDA, N. G. M. et al. Avaliação do efeito do branqueamento e tratamento enzimático na qualidade de suco de maçã. In: Embrapa Agroindústria de Alimentos-Artigo em anais de congresso (ALICE). In: CONGRESSO BRASILEIRO DE FRUTICULTURA, 21, 2010, Natal. Frutas: saúde, inovação e sustentabilidade: Anais. Natal: Sociedade Brasileira de Fruticultura, 2010. 1 CD-ROM., 2011

RUFINO, M.D.M., ALVES, R.E., DE BRITO, E.S., PEREZ-JIMENEZ, J., SAURACALIXTO, F., MANCINI, J. Bioactive compounds and antioxidant capacities of 18 nontraditional tropical fruits from Brazil. Food Chem, v. 121, p. 996-1002, 2010.

SILVA, E.M.; ROGEZ, H.; LARONDELLE, Y. Optimization of extraction of phenolics from Inga edulis leaves using response surface methodology. Separation and Purification Technology, 2007.

SILVA FILHO, D,; ANDRADE, J. S.; CLEMENT, C. R.; MACHADO , F. M.; NODA, H.; Correlações fenotípicas, genéticas e ambientais entre descritores Morfológicos e Químicos em frutos de Cubiu (Solanum sessiliflorum Dunal) da Amazônia1. Acta Amaz., Manaus, v. 29, n. 4, p. 503-511, Dec. 1999

SINGLETON, V.L.; ORTHOFER, R.; LAMUELA-RAVENTÓS, R. Analysis of total phenols and other oxidation substrates and antioxidants by means of Folin-Ciocalteu reagent. Methods in Enzymology, p. 152-178, 1999.

TABARAKI, R.; HEIDARIZADI, E.; BENVIDI, A. Optimization of ultrasonic-assisted extraction of pomegranate (Punica granatum L.) peel antioxidants by response surface methodology. Separation and Purification Technology, v.98, p.1623, 2012.

YUYAMA, L. K. O. ; PEREIRA, Z. R. F.; AGUIAR, J. P. L.; SILVA FILHO, D. F.; SOUSA, R. F. S. ; TEIXEIRA, A. P. Estudo da influência do cubiu (Solanum sessiliflorum Dunal) sobre a concentração sérica de glicose. Revista do Instituto Adolfo Lutz, São Paulo. v. 64, n.2, p. 232-236, 2006.

YUYAMA, L. K. O. ; OLIVEIRA, L. P. d.; MAEDA, R. N ; AGUIAR, J. P. L.; SILVA, S. B. D. Desenvolvimento e aceitabilidade da geléia dietética de cubiu (Solanum sessiliflorum Dunal). Ciência e Tecnologia de Alimentos, v. 28, p. 929-934, 2008. 